\title{
Bailout Thrombectomy: Its Outcomes in Patients Undergoing Primary Percutaneous Coronary Intervention
}

\author{
MAHBOOB UR REHMAN ${ }^{1}$, FARHAN FAISAL 2 , AMJAD ABRAR ${ }^{3}$, AMJAD ALI SHAH ${ }^{4}$, MUHAMMAD SHOAIB $^{5}$, \\ MALIK ALI RAZA 6 \\ ${ }_{1,2}$ Assistant Professor, Cardiac Centre Pakistan Institute of Medical Sciences, Islamabad \\ ${ }^{3}$ Associate Professor, Cardiology department, Gomal Medical College Dera Ismail Khan \\ ${ }^{4}$ Senior Medical Officer, Cardiology Department, Saidu Teaching Hospital Swat \\ ${ }_{5,6}$ Registrar Cardiology Department, Pakistan Institute of Medical Sciences, Islamabad \\ Corresponding Author: Dr Mahboob ur Rehman, Email:drmehboobfcps@yahoo.com, Cell No.03339229552
}

\begin{abstract}
Aim: To determine the clinical outcomes of patients who received bailout thrombectomy for primary percutaneous coronary intervention.

Study Design: Cross-sectional/observational

Place \& Duration: Study was conducted at Cardiac Centre, Cardiology Department, Pakistan Institute of Medical Sciences (PIMS) Islamabad from January 2020 to December 2020 (for one year).

Methods: 200 hundred patients of both genders undergoing primary percutaneous coronary intervention(PPCl)for ST elevation myocardial infarction(STEMI) were analyzed in this study. All patients were divided into two groups. Group A contains 100 patients and received PPCl with bailout thrombectomy and Group B contains 100 patients and received PPCI alone. Informed written consent was taken. Outcomes such as mortality, re-infarction, heart failure, cardiogenic shock, renal impairment, excess bleeding, post procedure stroke and hospital stay were examined and compare between both groups.

Results: In Group A there were 53\% males and 47\% females with mean age $56.45+10.88$ years. In Group B 55\% were males and $45 \%$ were females with mean age $58.35+9.23$ years. In Groups A there were more diabetic patients 45\% than Group B 32\% (p-value 0.005), Group B had more smokers 60\%. There was a significant difference between group $A$ and $B$ regarding family history of coronary artery disease $35 \%$ vs $20 \%(p=0.003)$. In Group A 3\% patients were died and in Group B 2\% patients were died with no significant difference. Group A patients had more renal impairment $9 \%$ vs $5 \%$ and stroke $3 \%$ vs $1 \%$ than Group B. Hospital stay was high in Group A patients $7.12+2.05$ vs $5.34+1.02$ days of Group B.

Conclusion: It is concluded that patients received bailout thrombectomy for percutaneous coronary intervention $(\mathrm{PCl})$ had high rate of comorbidities. There was no significant difference in term of mortality between both groups. However, patients with bailout thrombectomy had more renal impairment and post-procedure stroke.
\end{abstract}

Keywords: ST-segment elevated myocardial infarction, bailout thrombectomy, PPCl, Outcomes

\section{INTRODUCTION}

Globally, acute myocardial infarction (AMI) is one of the leading causes of morbidity and mortality in cardiac patients and acute coronary artery thrombosis is the major cause of ST-segment elevated myocardial infarction (STEMI) [1]. In these patients aspiration thrombectomy for primary percutaneous coronary intervention (PPCl) considered a useful management [1-2]. Aspiration thrombectomy is mostly not useful procedure in patients who presented in the early hours after the event occur. Many of studies reported that aspiration thrombectomy had major adverse outcomes in patients presented in early hours [3]. Patients presented late after the event occur the procedure aspiration thrombectomy considered a procedure of choice with better outcomes [3-4].

After the AMI, myocardial blush grade (MBG) and Thrmbolysis In Myocardial Infarction (TIMI) flow is a main predictor of mortality and morbidity. Routine aspiration thrombectomy during $\mathrm{PCl}$ in STEMI patients is associated to high rate of stroke [4-6]. Therefore, routine aspiration thrombus is considered not useful procedure in patients with STEMI. [7]. Aspiration thrombus is very effective with very low rate of mortality and cardiovascular morbidity in patients having TIMI thrombus grade $>3$. Thus, in this condition bailout throbectomyconsideredan effective and useful procedure. Many of studies demonstrated that bailout thrombectomy for $\mathrm{PCl}$ had low mortality rate in patients having thrombus grade $>3$ [7-9].

The present study was conducted aimed to examine the outcomes of bailout thrombectomy for PPCI in patients presented with acute STEMI and compare the findings with patients who received $\mathrm{PCl}$ alone.

\section{METHODS}

This cross-sectional study was conducted at Cardiac Centre, Cardiology Department, Pakistan Institute of Medical Sciences (PIMS) Islamabad from January 2020 to December2020(for one year). In this study total 200 patients of both genders with ages above 35 years presented with acute ST-segment elevated myocardial infarction (STEMI) undergoing Primary Percutaneous Coronary Intervention (PPCI) were included. Patients detailed demographic including, age, gender, residence, co-morbidities such as diabetes mellitus, hypertension, smoking history and hypercholesterolemia, history of liver disease and renal disease were examined after taking informed written consent. Patients who were presented late after 24 hours with STEMI, those who required Coronary Artery Bypas Grafting (CABG)and those with no consent were excluded.

All the patients were divided in to two groups. Group A contains 100 patients and received PPCI with bailout 
thrombectomy and Group B consist of 100 patients and received primary percutaneous coronary intervention alone. Outcomes such as mortality, re-infarction, heart failure, cardiogenic shock, renal impairment, excess bleeding, post-procedure stroke and hospital stay were examined and compare between both groups.

Data was analyzed by SPSS 20.0. Student t-test and chi-square test was used to compare the outcomes between both groups. Frequencies and percentages were obtained to analyze the values in tabulation form. P-value $<0.05$ was set as statistically significant.

\section{RESULTS}

In Group A there were $53 \%$ males and $47 \%$ females with mean age $56.45+10.88$ years. In Group B $55 \%$ were males and $45 \%$ were females with mean age $58.35+9.23$ years. There were $52 \%$ and $45 \%$ patients in Group A and B had rural residency while $48 \%$ and $55 \%$ patients in Group $A$ and B had urban residency. In Group A 45\% patients had diabetes mellitus while in Group B $32 \%$ had diabetes mellitus. Hypertension found in 35\% in Group A and 32\% in Group B. Hypercholesterolemia found in $60 \%$ and $59 \%$ in Group A and B. There were more smokers $60 \%$ in Group B than $38 \%$ in Group A patients. Liver disease found in 10\% and $21 \%$ patients in Group A and B. History of renal disease found in $22 \%$ and $10 \%$ patients in Group A and B. There were no significant difference regarding previous history of coronary artery disease, myocardial infarction and percutaneous coronary intervention $(p=>0.05)$. There was a significant difference between group $A$ and $B$ regarding family history of coronary artery disease $35 \%$ vs $20 \%(p=0.003)$. (Table 1$)$

\begin{tabular}{|c|c|c|c|}
\hline Characteristics & Group A & Group B & $\mathrm{P}$-value \\
\hline Mean Age yrs & $56.45+10.88$ & $58.35+9.23$ & 0.062 \\
\hline \multicolumn{4}{|l|}{ Gender } \\
\hline Male & $53(53 \%)$ & $55(55 \%)$ & $\mathrm{N} / \mathrm{S}$ \\
\hline Female & $47(47 \%)$ & $45(45 \%)$ & $\mathrm{N} / \mathrm{S}$ \\
\hline \multicolumn{4}{|l|}{ Residence } \\
\hline Rural & $52(52 \%)$ & $45(45 \%)$ & $\mathrm{N} / \mathrm{S}$ \\
\hline Urban & $48(48 \%)$ & $55(55 \%)$ & $\mathrm{N} / \mathrm{S}$ \\
\hline \multicolumn{4}{|l|}{ Comorbidities } \\
\hline Diabetes & $45(45 \%)$ & $32(32 \%)$ & 0.005 \\
\hline Hypertension & $35(35 \%)$ & $32(32 \%)$ & $\mathrm{N} / \mathrm{S}$ \\
\hline Hypercholesterolemia & $60(60 \%)$ & $59(59 \%)$ & $\mathrm{N} / \mathrm{S}$ \\
\hline History of Smoking & $38(38 \%)$ & $60(60 \%)$ & 0.001 \\
\hline History of CLD & $10(10 \%)$ & $21(21 \%)$ & 0.024 \\
\hline History of & $22(22 \%)$ & $10(10 \%)$ & 0.021 \\
\hline \multicolumn{4}{|l|}{ Cardiac factors } \\
\hline History of CAD & $8(8 \%)$ & $7(7 \%)$ & $\mathrm{N} / \mathrm{S}$ \\
\hline History of Ml & $9(9 \%)$ & $8(8 \%)$ & $\mathrm{N} / \mathrm{S}$ \\
\hline History of $\mathrm{PCl}$ & $10(10 \%)$ & $11(11 \%)$ & $\mathrm{N} / \mathrm{S}$ \\
\hline \multicolumn{4}{|l|}{ Family History of CAD } \\
\hline Yes & $35(35 \%)$ & $20(20 \%)$ & 0.003 \\
\hline No & $65(65 \%)$ & $80(80 \%)$ & \\
\hline
\end{tabular}

According to the clinical presentation we found $12 \%$ in Group A and $8 \%$ patients in Group B had cardiogenic shock. $18 \%$ and $15 \%$ in Group A and B had Killip class $>2$ heart failure, 35\% patients in Group A had early presentation within 12 hours while $65 \%$ patients had late presentation 12 to 24 hours. In Group B 33\% patients had early and $67 \%$ patients had late presentation. No significant difference between both groups. 54\% and 59\% patients had anterior myocardial infarction and $36 \%$ and $27 \%$ patients had inferior myocardial infarction in Group A and B. (Table 2)

Table No 2. Clinical findings between both groups
\begin{tabular}{|l|l|l|l|}
\hline Variables & Group A & Group B & P-value \\
\hline Cardiogenic Shock & $12(12 \%)$ & $8(8 \%)$ & 0.031 \\
\hline Class $>2$ HF & $18(18 \%)$ & $15(15 \%)$ & 0.049 \\
\hline Early Presentation & $35(35 \%)$ & $33(33 \%)$ & N/S \\
\hline Late Presentation & $65(65 \%)$ & $67(67 \%)$ & N/S \\
\hline Myocardial Infarction & $54(54 \%)$ & $59(59 \%)$ & 0.046 \\
\hline Anterior & $36(36 \%)$ & $27(27 \%)$ & 0.033 \\
\hline Inferior
\end{tabular}

In Group A 3\% patients were died and in Group B 2\% patients were died with no significant difference. Group A patients had more renal impairment $9 \%$ vs $5 \%$ and stroke $3 \%$ vs $1 \%$ than Group B. In Group A and B 5\% and 4\% patients had NYHA class IV heart failure. In Group A 3\% patients found to have excess bleeding and in Group B 2\% patients had excess bleeding. Re-infarction found in $4 \%$ and $2 \%$ patients in Group A and B. Hospital stay was high in Group A patients $7.12+2.05$ vs $5.34+1.02$ days. (Table 3 )

Table No 3. Outcomes of procedure between both groups

\begin{tabular}{|l|l|l|l|}
\hline Variables & Group A & Group B & P-value \\
\hline Died & $3(3 \%)$ & $2(2 \%)$ & $\mathrm{N} / \mathrm{S}$ \\
\hline Renal Imp & $9(9 \%)$ & $5(5 \%)$ & 0.04 \\
\hline Stroke & $3(3 \%)$ & $1(1 \%)$ & 0.048 \\
\hline HF & $5(5 \%)$ & $4(4 \%)$ & $\mathrm{N} / \mathrm{S}$ \\
\hline Excess Bleeding & $3(3 \%)$ & $2(2 \%)$ & $\mathrm{N} / \mathrm{S}$ \\
\hline Re-infarction & $4(4 \%)$ & $2(2 \%)$ & 0.049 \\
\hline Hospital stay (days) & $7.12+2.05$ & $5.34+1.02$ & 0.02 \\
\hline
\end{tabular}

\section{DISCUSSION}

Acute myocardial infarction (AMI) is one of the most common cardiac disorders. In USA about 0.6 million people found to have myocardial infarction categorized as ST elevation myocardial infarction (STEMI )[10]. Every year 0.12 million people have undergo percutaneous coronary intervention [11]. Present study was conducted aimed to examine the outcomes of primary percutaneous coronary intervention (PPCl) with bailout thrombectomy in patients presented with STEMI. In this study we analyzed 200 patients whom were undergoing PPCI. We divided patients into two groups Group A and B. Group A consist of those patients who received bailout thrombectomy for $\mathrm{PCl}$ and Group B received $\mathrm{PCl}$ alone. We found that There were no significant difference regarding gender and age wise distribution between both groups. These results were similar to some other studies [12-13].

In present study we found that in Group A 45\% patients had diabetes mellitus while in Group B 32\% had diabetes mellitus. Hypertension found in $35 \%$ in Group A and $32 \%$ in Group B. Hypercholesterolemia found in $60 \%$ and $59 \%$ in Group A and B. There were more smokers $60 \%$ in Group B than 38\% in Group A patients. These results were comparable to some other studies [14-15]. In this study we found a significant difference between group $A$ and $B$ regarding family history of coronary artery disease $35 \%$ vs $20 \% \quad(p=0.003)$. A study conducted by Mona $A$ alsaidy [16] reported no difference in term of family history of coronary artery disease.

In present study Group A patients had more cardiogenic shock and killip class $>2$ heart failure than the patients treated $\mathrm{PCl}$ alone. These results were similar to 
other study in which patients who received bailout thrombectomy for PPCI had increase rate of cardiogenic shock [17].

In our study we found In Group A 3\% patients were died and in Group B 2\% patients were died with no significant difference. These results were similar to some other studies in which no major difference was found in term of mortality between patients who received aspiration thrombectome and patients who received $\mathrm{PCl}$ alone [18]. We found that group A patients had more renal impairment $9 \%$ vs $5 \%$ and stroke $3 \%$ vs $1 \%$ than Group B. In Group A and B 5\% and $4 \%$ patients had NYHA class IV heart failure. In Group A 3\% patients found to have excess bleeding and in Group B $2 \%$ patients had excess bleeding. Re-infarction found in 4\% and $2 \%$ patients in Group $A$ and B. Hospital stay was high in Group A patients $7.12+2.05$ vs $5.34+1.02$ days. These results were comparable to some other studies [19-20].

\section{CONCLUSION}

We concluded that patients received bailout thrombectomy for percutaneous coronary intervention had high rate of comorbidities. There was no significant difference in term of mortality between both groups. However, patients with bailout thrombectomy had more renal impairment and postprocedure stroke. More patients had major bleeding and length of hospital stay was also high in patients who received bailout thrombectomy.

\section{REFERENCES}

1. Nahlawi G, Brener SJ. Thrombus aspiration in acute myocardial infarction. IntervCardiol 2013;5(6):673-81.

2. Desch S, Stiermaier T, De Waha S, Lurz P, Gutberlet M, Sandri $M$, et al. Thrombus aspiration in patients with ST segment elevation myocardial infarction presenting late after symptom onset. J Am Coll Cardiollntv 2016;9(2):113-22.

3. Ikari Y, Sakurada M, Kozuma K, Kawano S, Katsuki T, Kimura $\mathrm{K}$, et al. Upfront thrombus aspiration in primary coronary intervention for patients with ST-segment elevation acute myocardial infarction: report of the VAMPIRE (Vacuum Aspiration Thrombus Removal) trial. JACC Cardiovasc Interv 2008;1(4):424-31.

4. Gibson CM, Cannon CP, Murphy SA, Ryan KA, Mesley R, Marble SJ, et al. Relationship of TIMI myocardial perfusion grade to mortality after administration of thrombolytic drugs. Circulation 2000;101(2):125-30.

5. Henriques JP, Zijlstra F, van't Hof AW, de Boer MJ,Dambrink $\mathrm{JH}$, Gosselink $\mathrm{M}$, et al. Angiographic assessment of reperfusion in acute myocardial infarction by myocardial blush grade. Circulation 2003;107(16):2115-9.

6. van't Hof AW, Liem A, Suryapranata H, Hoorntje JC, de Boer MJ, Zijlstra F. Angiographic assessment of myocardial reperfusion in patients treated with primary angioplasty for acute myocardial infarction: myocardial blush grade. Zwolle Myocardial Infarction Study Group. Circulation 1998;97(23):2302-6.

7. Cairns JA, Yusuf S, Rokoss MJ, Gao P, Meeks B, et al. Outcomes after thrombus aspiration for ST elevation myocardial infarction: 1-year follow-up of the prospective randomized TOTAL trial. Lancet 2016;387(10014):127-35.
8. Ibanez B, James S, Agewall S, Antunes MJ, BucciarelliDucci C, Bueno H, et al. 2017 ESC Guidelines for the management of acute myocardial infarction in patients presenting with ST-segment elevation: The Task Force for the management of acute myocardial infarction in patients presenting with ST-segment elevation of the European Society of Cardiology (ESC). Eur Heart J 2018;39(2):119-77.

9. National Cardiovascular Data Registry. NCDR CathPCl Registry. Institutional Outcomes Report 2015 Q2. National Outcomes Report 999997. NCDR CathPCI Registry National Outcomes Report, 1-72. 20161.

10. Mozaffarian D, Benjamin EJ, Go AS, et al; American Heart Association Statistics Committee and Stroke Statistics Subcommittee. Heart disease and stroke statistics-2016 update: a report from the American Heart Association. Circulation. 2016;133(4):e38-e360.

11. Vecchio S, Varani E, Chechi T, et al. Coronary thrombus in patients undergoing primary PCI for STEMI. World J Cardiol. 2014;6(6):381-392.

12. Cairns JA, Yusuf S, Meeks B, Pogue J, RokossMJ, et al.

13. Randomized trial of primary $\mathrm{PCl}$ with or without routine manual thrombectomy. N En g I J Med 2015;372(15):138998.

14. Sharma V, Jolly SS, Hamid T, Sharma D, Chiha J, Chan W, Fuchs F, Bui S, Gao P, Kassam S, Leung RC, Horák D, Romppanen HO, ElOmar M, Chowdhary S, Stanković G, Kedev S, Rokoss MJ, Sheth T, Džavík V, Overgaard CB. Myocardial blush and microvascular reperfusion following manual thrombectomy during percutaneous coronary intervention for ST elevation myocardial infarction: insights from the TOTAL trial. Eur Heart J. 2016;37:1891-1898.

15. Sahin M, Acar G, Kalkan ME, Acar RD, Kilicgedik A, Teymen $\mathrm{B}$, Arslantas U, Kirma C. Thrombus aspiration during primary percutaneous coronary intervention associated with reduced platelet activation. Saudi Med J. 2015;36:935-939.

16. Mona A Alsaidy et al. study the baseline characteristics, angiographic variables and clinical outcomes of patients going for primary $\mathrm{PCl}(\mathrm{PPCl})$ who needed bailout thrombectomy and compare them to patients going for ( PPCI) alone. Pak J Heart; 2018 Vol. 51 (03) : 189 - 195.

17. Lee WC, Fang CY, Chen HC, Hsueh SK, Chen CJ, Yang $\mathrm{CH}$, Yip HK, Hang CL, Wu CJ, Fang HY. Aspiration thrombectomy and drug-eluting stent implantation decrease the occurrence of angina pectoris one year after acute myocardial infarction. Medicine. 2016;95:e3426.

18. Geng T, Zhang JG, Song ZY, Dai SP, Luo Y, Xu ZS. Aspiration thrombectomy and intracoronary tirofiban in stsegment elevation myocardial infarction: combination treatment for patients undergoing primary percutaneous coronary intervention. Herz. 2016;41:732-740.

19. Lagerqvist B, Olivecrona GK, Omerovic E, Gudnason T, Maeng $\mathrm{M}$, et al. Thrombus aspiration during ST segment elevation myocardial infarction. $N$ Engl $J$ Med 2013;369(17):1587-97. [Erratum Published in N Engl J Med 2014;371(8):786.]

20. Olivecrona GK, Lagerqvist $B$, Fröbert $O$, Gudnason $T$, Maeng $M$, Råmunddal $T$, Haupt $\mathrm{J}$, Kellerth $\mathrm{T}$, Stewart $\mathrm{J}$, Sarno G, Jensen J, Östlund O, James SK. Impact of thrombus aspiration during ST-elevation myocardial infarction: a six month composite endpoint and risk of stroke analyses of the TASTE trial. BMC Cardiovasc Disord. 2016;16:62. 